\title{
Metabolic and Functional Consequences of Inhibiting Adenosine Deaminase during Renal Ischemia in Rats
}

\author{
Michael E. Stromski," Aren van Waarde," Malcolm J. Avison," Gunilla Thulin, ${ }^{5}$ Karen M. Gaudio," \\ Michael Kashgarian, ${ }^{\ddagger}$ Robert G. Shulman, ${ }^{*}$ and Norman J. Siegel \\ Departments of Molecular Biophysics and Biochemistry,* Pathology, ${ }^{*}$ and Pediatrics, $\$$ \\ Yale University School of Medicine, New Haven, Connecticut 06510
}

\begin{abstract}
The concentrations of renal ATP have been measured by ${ }^{31} \mathrm{P}$ nuclear magnetic resonance (NMR) before, during, and after bilateral renal artery occlusion. Using in vivo NMR, the initial postischemic recovery of ATP increased with the magnitude of the residual nucleotide pool at the end of ischemia. ATP levels after 120 min of reflow correlated with functional recovery at $24 \mathrm{~h}$. In the present study the effect of blocking the degradation of ATP during ischemia upon the postischemic restoration of ATP was investigated. Inhibition of adenosine deaminase by $80 \%$ with the tight-binding inhibitor 2 -deoxycoformycin led to a $20 \%$ increase in the residual adenine nucleotide pool. This increased the ATP initial recovery after $45 \mathrm{~min}$ of ischemia from $52 \%$ (in controls) to $62 \%$ (in the treated animals), as compared to the basal levels. The inhibition also caused an accelerated postischemic restoration of cellular ATP so that at $120 \mathrm{~min}$ it was $83 \%$ in treated rats vs. $63 \%$ in untreated animals. There was a corresponding improvement in the functional recovery from the insult (increase of $33 \%$ in inulin clearance $24 \mathrm{~h}$ after the injury). Inhibition of adenosine deaminase during ischemia results in a injury similar to that seen after a shorter period of insult.
\end{abstract}

\section{Introduction}

It is well known that renal ischemia causes a depletion of cellular ATP (1-11) and that after the insult the recovery of ATP is incomplete (1-4, 6-12). Previous work from our laboratory has shown that the postischemic restoration of renal ATP is a biphasic process $(4,6-8)$. There is a rapid initial recovery of cellular ATP $\left(\mathrm{ATP}_{\text {init }}\right)^{1}$ immediately upon reflow followed by a slower, more gradual return toward preischemic levels. This pattern of recovery is operative over a wide range

Dr. Stromski's present address is Renal Division, Brigham and Women's Hospital, Boston, MA 02115 . Address reprint requests to Dr. Siegel.

Received for publication 25 January 1988 and in revised form 14 June 1988.

1. Abbreviations used in this paper: ADA, adenosine deaminase; $\mathrm{ATP}_{\text {init }}$, rapid initial recovery of renal ATP, $\mathrm{ATP}_{\text {slope }}$, rate of net restoration of renal ATP; ATP $_{120}$, cellular ATP content after $120 \mathrm{~min}$ of reflow; ATP- $\beta, \beta$-phosphate ATP; $C_{\text {in }}$, inulin clearance; DCF, $2^{\prime}$ deoxycoformycin; NMR, nuclear magnetic resonance; TAN, total adenine nucleotide(s).

J. Clin. Invest.

(c) The American Society for Clinical Investigation, Inc.

0021-9738/88/11/1694/06 \$2.00

Volume 82, November 1988, 1694-1699 of ischemic intervals. The amplitude of the $A T P_{\text {init }}$ decreased with the duration of ischemia and was also shown to be a monatomic function of the total adenine nucleotide (TAN) pool at the end of the ischemic period. Furthermore, the renal ATP content after 120 min of reflow has been shown to be a good predictor of the functional recovery of the kidney $24 \mathrm{~h}$ later (8).

Based on these observations, we proposed that the metabolic and functional severity of renal ischemia was related to the degree of loss of residual nucleotides during ischemia. There was also a dependence upon the capacity of the kidney to regenerate ATP during reflow, but the chemical correlation of this dependence was not defined by these early experiments. To evaluate the hypothesis that the $\mathrm{ATP}_{\text {init }}$ depended upon the TAN, we investigated whether enhancement of the residual nucleotide pool by inhibition of ATP degradation ameliorates the metabolic and functional consequences of renal ischemia.

\section{Methods}

Male Sprague-Dawley rats (200-250 g) were used for all experiments. Adenosine, nucleoside phosphorylase (crystalline ammonium sulfate suspension from calf spleen), xanthine oxidase (crystalline ammonium sulfate suspension from buttermilk), imidazole, sucrose, and bovine serum albumin (BSA) were purchased from Sigma Chemical Co. (St. Louis, MO). 2'-deoxycoformycin (DCF) was generously donated by Warner Lambert Co (Ann Arbor, MI). [methoxy- ${ }^{3} \mathrm{H}$ ]methoxyinulin was purchased from New England Nuclear (Boston, MA).

Enzyme preparation. Adenosine deaminase (ADA) was prepared from the kidneys of all rats by a modification of the procedure of Tedde et al. (13). Kidneys were excised, cooled, and homogenized as 50\% (wt/vol) solutions in $250 \mathrm{mM}$ sucrose/50 mM imidazole-HCl, pH 7.0. Homogenates were centrifuged at $10,000 \mathrm{~g}$ for $30 \mathrm{~min}$. BSA $(0.5$ $\mathrm{mg} / \mathrm{ml}$ ) was added to the supernatant to stabilize the enzyme activity (14). The preparation was then exhaustively dialyzed against $50 \mathrm{mM}$ imidazole- $\mathrm{HCl} / 100 \mathrm{mM} \mathrm{NaCl}, \mathrm{pH}$ 7.0. ADA activity was determined as described below.

Enzyme assay. ADA activity in kidneys of experimental rats was determined by a modification of the assay of Hopkinson et al. (15) in which the inosine produced is converted to uric acid in the presence of excess commercial nucleoside phosphorylase and xanthine oxidase. The reaction mixture contained $0.1 \mathrm{mM}$ exogenous adenosine, nucleoside phosphorylase $(0.1 \mathrm{U} / \mathrm{ml})$, xanthine oxidase $(0.2 \mathrm{U} / \mathrm{ml})$, and $0.25 \mathrm{ml}$ of the kidney homogenate in a $50 \mathrm{mM}$ imidazole- $\mathrm{HCl} / 100$ $\mathrm{mM} \mathrm{NaCl}$ (pH 7.0) buffer. The decrease in adenosine was monitored by a decline in absorbance at $265 \mathrm{~nm}$. A millimolar extinction coefficient of 12.5 was measured and used to convert absorbance decreases to millimoles of adenosine deaminated. One unit of enzyme activity is defined as the amount of enzyme that catalyzes the conversion of 1 $\mu$ mol of adenosine to inosine in $1 \mathrm{~min}$ under the specified steady-state assay conditions. For specific activity determinations, protein was quantitated by the method of Lowry et al. (16) using BSA as the standard.

$D C F$ injection. DCF $(0.5-2.0 \mathrm{mg} / \mathrm{kg})$ was injected intramuscularly $24 \mathrm{~h}$ before the appropriate experiment was to be performed. Similar 
results were obtained throughout the dose range. In animals treated with DCF, data were disregarded if the level of ADA inhibition was $<80 \%$. Control animals received either an injection of saline or no treatment.

In vivo nuclear magnetic resonance (NMR). The rats were anesthetized with sodium thiobutabarbital (Inactin, $80 \mathrm{mg} / \mathrm{kg}$, i.p.) and tracheotomized. A catheter was inserted into the right jugular vein for the infusion of normal saline. A midline abdominal incision and blunt dissection were used to expose the renal arteries. A silastic sling was looped around the aorta proximal to the origin of both renal arteries and distal to the origin of the celiac artery. The silastic sling was brought out through the abdominal incision, which was then closed. The left kidney was exposed via a flank incision and cleaned of surrounding fat and tissue. The kidney was then placed in a micropuncture cup modified to contain the NMR radiofrequency coil. Body temperature was maintained at $36.5-37.5^{\circ} \mathrm{C}$ with a recirculating water bed. Animals were heparinized $(500 \mathrm{U} / \mathrm{kg}$ ) and surgical fluid losses were replaced with normal saline ( $2 \%$ of body weight). A maintenance infusion of normal saline $(1.2 \mathrm{ml} / \mathrm{h})$ was given continuously throughout the experiment.

Our method for in vivo ${ }^{31} \mathrm{P}-\mathrm{NMR}$ spectroscopy has previously been described (4, 6-8). Spectra were obtained on a Biospec 4.7T system (Bruker Instruments, Inc., Billerica, MA) operating at $200 \mathrm{MHz}$ for protons and $81.1 \mathrm{MHz}$ for ${ }^{31} \mathrm{P}$ (Fig. 1). Magnetic field homogeneity was optimized by shimming on the water ${ }^{1} \mathrm{H}$ signal. ${ }^{31} \mathrm{P}$ spectra consisted of 2,048 acquisitions using $53^{\circ}$ pulses and $0.2-s$ recycle times. In separate experiments, $T_{1}$ of the peak of $\beta$-phosphate ATP (ATP- $\beta$ ) was measured to be $\sim 0.4 \mathrm{~s}$ in the basal state in the kidney at $4.7 \mathrm{~T}$. The $53^{\circ}$ pulse was calculated as the Ernst angle designed to maximize signalto-noise (Fig. 1). An aqueous solution of methylphosphonate and Gd $\mathrm{Cl}_{3}$ was attached to the micropuncture cup for use as an external standard. Three control spectra were collected to ensure that the preparation was well energized and stable. The kidneys were then made ischemic for $\mathbf{4 5} \mathrm{min}$ by placing tension on the silastic sling. After the ischemic interval, the tension on the sling was released and the animal allowed to recover for $120 \mathrm{~min}$. At the end of this period, the kidneys

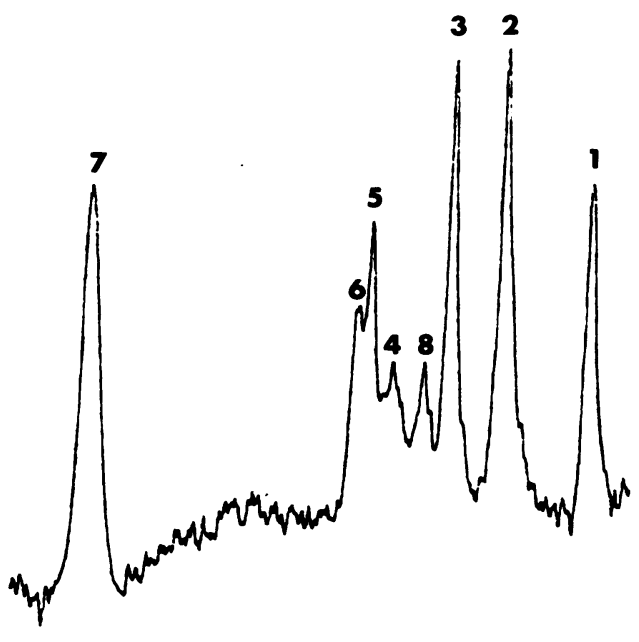

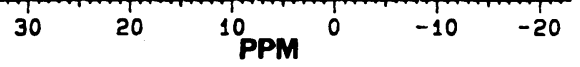

Figure 1. ${ }^{31} \mathrm{P}-\mathrm{NMR}$ spectrum obtained in vivo from the left kidney prior to ischemia. Spectra were acquired on a Brucker Biospec 4.7T system and consisted of 2,048 acquisitions using $53^{\circ}$ pulses and $0.2-\mathrm{s}$ recycle time. Peak assignments: (1) ATP- $\beta$, (2) ATP- $\alpha$, (3) ATP- $\tau$, (4) phosphodiester, (5) $P_{i}$, (6) sugar phosphate, (7) methylphosphonate with $\mathrm{GdCl}_{3},(8) \mathrm{PCr}$. were excised and ADA activity was measured as described above. Since spectra were collected before, during, and after the ischemic insult, each animal served as its own control. Renal ATP levels were assessed by comparing changes in the intensity of the ATP- $\beta$ peak. In each spectrum, the height of the ATP- $\beta$ peak was measured relative to that of the methylphosphonate peak. The line widths of both peaks were measured during the basal period and reflow. Since the widths were constant, the relative height gave ATP concentrations. Changes in renal ATP are expressed as a percentage of the preischemic control value.

Since the ATP- $\beta$ peak was partially saturated with the $53^{\circ}$ pulse and 0.2 -s recycle time, it was matched to the methylphosphonate peak where $T_{1}$ was reduced to $0.4 \mathrm{~s}$ by the addition of $\mathrm{GdCl}_{3}$. In this way changes in the intensity of the ATP- $\beta$ peak from variations in the $r_{f}$ would be canceled. Since $T_{1}$ of the ATP- $\beta$ during recovery could not be measured accurately because of the transient nature of the recovery period, it was possible that changes in $T_{1}$ during recovery occurred and were influencing the accuracy of determining the ATP concentration. As described in Results below, the initial recovery of ATP relative to control values, observed by ${ }^{31} \mathrm{P}-\mathrm{NMR}$ in vivo, was confirmed by ${ }^{1} \mathrm{H}$ NMR values of ATP concentrations measured in perchloric acid extracts. Hence there is no reason to believe that errors have been introduced into the in vivo ATP determination by possible variations in $T_{1}$ of the ATP- $\beta$.

As previously described $(4,6-8)$, time-course data for ATP recovery were provided by analysis of linear regression lines calculated from all the data points collected during the $120 \mathrm{~min}$ of reflow for each experiment. The initial rapid recovery of ATP $\left(\mathrm{ATP}_{\text {init }}\right)$ was determined from the $y$-intercept of the linear regression line, the rate of net restoration of renal ATP was evaluated from the slope (ATP slope), and ATP $_{120}$ was defined as the tissue ATP concentration after $120 \mathrm{~min}$ of reflow.

Extract studies. Animals were prepared as described for in vivo studies. To determine purine breakdown products at the end of $45 \mathrm{~min}$ of bilateral renal artery occlusion, the kidneys were quickly frozen in situ with aluminum tongs cooled in liquid nitrogen and extracted with perchloric acid by well-established methods (17). In three treated and three control animals, the kidneys were harvested after $15 \mathrm{~min}$ of reflow. Data obtained in these studies were compared to values from nonischemic kidneys which had been harvested and processed by the same methods (8). In DCF-treated animals, one kidney was used for chemical analysis while the other kidney was excised and used to determine the level of enzyme inhibition. The protein-free extracts were triply lyophilized in ${ }^{2} \mathrm{H}_{2} \mathrm{O} .{ }^{1} \mathrm{H}-\mathrm{NMR}$ spectra of these extracts were obtained at $500 \mathrm{MHz}$ on a Bruker WM 500 spectrometer. Spectra consisted of 200 acquisitions using $90^{\circ}$ pulses and 10-s recycle times. Peak assignments were made by comparison with standard spectra and by sequential addition of the compounds to extracts (8). Concentrations of the adenine nucleotides, nucleosides, and hypoxanthine were calculated using glycerophosphorylcholine as an internal concentrating standard (Fig. 2).

Functional studies. Animals were anesthetized with sodium pentobarbital $(50 \mathrm{mg} / \mathrm{kg})$ and subjected to $45 \mathrm{~min}$ of bilateral renal artery occlusion as previously described. At the end of this insult the catheters were removed and the animal was allowed free access to food and water. Kidney function was determined by inulin clearance $24 \mathrm{~h}$ after the injury (18). The animals were anesthetized with Inactin $(80 \mathrm{mg} / \mathrm{kg}$, i.p.) and tracheotomized. Catheters were inserted into the right jugular vein and bladder. After replacement of surgical fluid losses with normal saline, a priming dose of $10 \mu \mathrm{Ci}$ of [methoxy $\left.{ }^{3} \mathrm{H}\right]$ methoxyinulin (inulin) was given, followed by a sustaining infusion of $10 \mu \mathrm{Ci} / \mathrm{h}$ in 1.2 $\mathrm{ml}$ of normal saline. After a 45-min equilibration period, inulin clearance $\left(C_{\mathrm{In}}\right)$ was determined by the average of three 10 -min urine collections. Blood samples were obtained from the tail at the midpoint of each urine collection. The concentration of inulin was determined with a liquid scintillation counter. $C_{\text {In }}$ was calculated using a standard formula (18). After the determination of $C_{\mathrm{In}}$ in DCF-injected rats, the kidneys were excised for measurement of the level of ADA inhibition. 


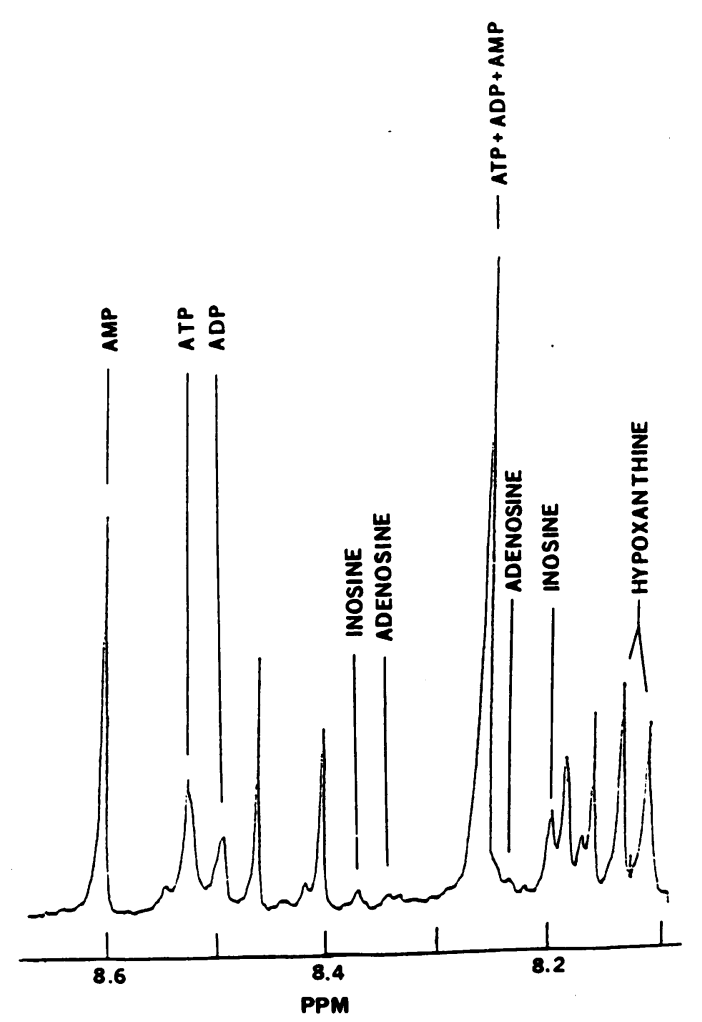

Figure 2. Representative high-resolution ${ }^{1} \mathrm{H}-\mathrm{NMR}$ spectrum of a rat kidney extracted with perchloric acid after $45 \mathrm{~min}$ of ischemia. Peaks are assigned as indicated. Chemical shifts are referenced to trimethylsilylpropionate at 0 PPM. Spectra are collected at $500 \mathrm{MHz}$ and consisted of 200 accumulations utilizing $90^{\circ}$ pulses and 10 -s recycle times.

Statistics. All values are expressed as mean \pm standard error of the mean. Linear regression lines were calculated using the method of least squares. Comparison between groups was made using analysis of variance and Student's $t$ test with Bonferroni's modification where applicable.

\section{Results}

The effect of intramuscular injections of DCF on renal ADA activity is shown in Table I. $24 \mathrm{~h}$ after the injection, $80 \%$ reduction in ADA activity was achieved. Subjecting the animal to ischemia at this time did not alter the effect of the drug on renal ADA activity. The inhibition was sustained for at least another $48 \mathrm{~h}$. Activity was not measured more than $72 \mathrm{~h}$ after the injection.

The effect of an injection of DCF $24 \mathrm{~h}$ before $45 \mathrm{~min}$ of renal ischemia on the concentrations of adenine nucleotides,

Table I. Effect of DCF on ADA Activity in the Rat Kidney

\begin{tabular}{lccc}
\hline Treatment & $\begin{array}{c}\text { Number of } \\
\text { animals }\end{array}$ & ADA activity & $\begin{array}{c}\text { Degree of } \\
\text { inhibition }\end{array}$ \\
\hline & & $\mu$ mol/min/mg protein & $\%$ \\
None & 6 & $0.0143 \pm 0.0026$ & - \\
DCF & 17 & $0.0030 \pm 0.0002$ & 79.0 \\
DCF $^{*}$ & 30 & $0.0028 \pm 0.0001$ & 80.4 \\
\hline
\end{tabular}

* Animals subjected to $45 \mathrm{~min}$ of ischemia. nucleosides, and hypoxanthine at the end of the insult is shown in Table II. The inhibition of ADA during ischemia led to a $20 \%$ increase in TAN (the sum of ATP, ADP, and AMP) content of the organ at the end of the insult. Adenosine was increased $\sim 2$.5-fold, whereas inosine and hypoxanthine were not detected in DCF-treated rats. The sum of adenosine, inosine, and hypoxanthine was significantly decreased in rats injected with the inhibitor.

At the initiation of ischemia the tissue concentration of ATP quickly decreased to levels that were undetectable with in vivo ${ }^{31} \mathrm{P}-\mathrm{NMR}$ and remained low for the duration of the insult. Table III gives the initial and subsequent (after $2 \mathrm{~h}$ of reflow) recoveries of renal ATP seen in both control and DCF-treated rats after $45 \mathrm{~min}$ of ischemia. Note that the DCF-treated rats subjected to a 45-min ischemic insult had an enhanced ATP $_{\text {init }}$ compared to untreated rats $(P<0.01)$. This enhancement of initial recovery of ATP in DCF treated animals was confirmed by ${ }^{1} \mathrm{H}-\mathrm{NMR}$ in vitro of the extracts of kidneys obtained after 15 min of reflow $(65 \pm 2 \%$ in DCF animals vs. $50 \pm 3 \%$ in controls, $P<0.05)$. As shown in Table III, the $\mathrm{ATP}_{\text {slope }}$ was also increased by treatment with DCF during the injury $(P<0.05)$. These two results led to a higher $\mathrm{ATP}_{120}(P<0.005)$. A direct comparison of the linear regression lines for control and DCFtreated rats (Fig. 3) shows that treatment with DCF prior to a 45-min period of renal ischemia accelerates the postischemic restoration of renal ATP by enhancing the rapid initial recovery and also by accelerating the rate of net restoration of this high-energy phosphate compound.

The effect of DCF on renal function was measured by $C_{\mathrm{In}}$. Injection of DCF did not affect $C_{\text {In }} 24 \mathrm{~h}$ after administration of the drug in control nonischemic animals $(1,099 \pm 101 \mu \mathrm{l} / \mathrm{min}$ per $100 \mathrm{~g}$ body weight in DCF-treated animals vs. $1,016 \pm 52$ in controls). Inhibition of ADA during $45 \mathrm{~min}$ of ischemia resulted in significantly improved renal function $24 \mathrm{~h}$ (Table III) after the injury $(398 \pm 35)$ as compared to control animals $(300 \pm 19, P<0.05)$.

\section{Discussion}

Many investigators have shown that during a period of renal ischemia, the cellular ATP concentration significantly decreases (1-11) and after the insult, the recovery of this highenergy nucleotide is incomplete $(1-4,6-12)$. Previous studies from our laboratory using in vivo ${ }^{31} \mathrm{P}-\mathrm{NMR}$ have shown that the postischemic restoration of renal ATP is a biphasic process $(4,6-8)$. There is a rapid initial recovery of cellular ATP immediately upon reflow followed by a slower, more gradual component. Investigation of this pattern of ATP restoration as a function of various ischemic intervals found that $(a)$ the magnitude of the initial recovery of ATP is a good indicator of the residual adenine nucleotide pool in the kidney at the end of the insult, $(b)$ the slower phase that measures the rate of net restoration of renal ATP has a mechanism which is still undefined, and $(c)$ the renal ATP content after 120 min of reflow is a good indicator of the recovery of glomerular function $24 \mathrm{~h}$ after the insult (8). Thus, the postischemic recovery of ATP is a function of the residual nucleotide pool at the end of ischemia as well as the rate at which the kidney restores this high-energy compound during the first $120 \mathrm{~min}$ after reflow.

The present study was designed to provide new information concerning the relationship between TAN catabolism, the salvage of the residual nucleotide pool, and the severity of an 
Table II. Concentrations of Purine Breakdown Products in the Rat Kidney after 45 min of Ischemia

\begin{tabular}{|c|c|c|c|c|c|c|c|c|c|}
\hline Treatment & $\begin{array}{l}\text { Number of } \\
\text { animals }\end{array}$ & $A T P$ & $A D P$ & $A M P$ & TAN & Adenosine & Inosine & Hypoxanthine & Total \\
\hline & & \multicolumn{8}{|c|}{$\mu \mathrm{mol} / \mathrm{g}$ wet weight } \\
\hline None & 5 & $0.33 \pm 0.04$ & $0.31 \pm 0.07$ & $0.89 \pm 0.15$ & $1.53 \pm 0.17$ & $0.09 \pm 0.02$ & $0.19 \pm 0.04$ & $0.67 \pm 0.15$ & $0.95 \pm 0.16$ \\
\hline DCF & 5 & $0.48 \pm 0.11$ & $0.38 \pm 0.11$ & $1.62 \pm 0.16^{*}$ & $2.48 \pm 0.22^{*}$ & $0.22 \pm 0.03^{*}$ & BLD & BLD & $0.22 \pm 0.3$ \\
\hline
\end{tabular}

DCF was given intramuscularly $24 \mathrm{~h}$ before ischemia. TAN $=($ ATP + ADP + AMP $)$. BLD, below the limits of detection. ${ }^{*} P<0.05$ compared to untreated animals.

ischemic renal insult. In addition, these studies offered an opportunity to test our model of the biphasic restoration of cellular ATP after renal ischemia. It has previously been shown in heart tissue $(19,20)$ that inhibition of an enzyme in the degradative pathway of ATP will increase the magnitude of the residual nucleotide pool in the organ after an ischemic insult. Therefore, by our model, inhibition of an enzyme in the degradative pathway of ATP would be expected to increase the magnitude of the residual nucleotide pool at the end of ischemia, which should be measured by increased $\mathrm{ATP}_{\text {init }}$, and might lead to an increased $\mathrm{ATP}_{120}$, which could be associated with improvement in renal function (reflected by increased $C_{\text {In }}$ ).

DCF is a competitive, tight-binding inhibitor of ADA (21), the enzyme that catalyzes the deamination of adenosine to inosine. In vitro studies have shown that it is possible to completely abolish the activity of this enzyme by the addition of DCF to the enzyme preparation (21). In vivo studies have demonstrated that ADA activity can be significantly reduced in most tissues by an injection of DCF, although different tissues have varied sensitivities to the inhibitory effect of the drug $(13,14,22,23)$. Inhibiting this enzyme during a period of renal ischemia should lead to an increase in the tissue concentration of adenosine. This, in turn, would be expected to result in an enhanced residual adenine nucleotide pool in the organ at the end of the insult, as adenosine is an end-product inhibitor of 5'-nucleotidase, the enzyme catalyzing the dephosphorylation of AMP to adenosine. By using an intramuscular injection protocol, it was possible to achieve consistently an $\mathbf{8 0 \%}$ reduction in renal activity of ADA by means of doses of DCF as low as $0.5 \mathrm{mg} / \mathrm{kg}$. This inhibition was sustained for at least $72 \mathrm{~h}$ after the injection. Furthermore, subjecting the animal to

Table III. Effect of Treatment with DCF on Postischemic Recovery of Renal ATP and Inulin Clearance

\begin{tabular}{llc}
\hline & $\begin{array}{c}45-\text { min ischemia } \\
(n=8)\end{array}$ & $\begin{array}{c}45-\text { min ischemia with DCF } \\
(n=7)\end{array}$ \\
\hline $\operatorname{ATP}_{\text {init }}(\%$ control $)$ & $52.7 \pm 2.1$ & $62.5 \pm 2.5^{*}$ \\
$\operatorname{ATP}_{\text {slope }}(\%$ control/min $)$ & $0.11 \pm 0.03$ & $0.18 \pm 0.02^{\ddagger}$ \\
$\operatorname{ATP}_{120}(\%$ control $)$ & $62.0 \pm 2.8$ & $83.4 \pm 4.8^{*}$ \\
$\begin{array}{l}\text { Inulin clearance } \\
(\mu l / \text { min/100 g body weight })\end{array}$ & $300 \pm 19$ & $398 \pm 35^{\ddagger}$ \\
& & \\
\end{tabular}

DCF was given intramuscularly $24 \mathrm{~h}$ before ischemia. Inulin clearance was measured $24 \mathrm{~h}$ after ischemia.

$\mathrm{ATP}_{\text {init }}$, rapid initial recovery of renal ATP; ATP $_{\text {slope }}$, rate of net restoration of renal ATP; ATP ${ }_{120}$, cellular ATP content after $120 \mathrm{~min}$ of reflow; ${ }^{*} P<0.01$ compared to untreated group. ${ }^{\ddagger} P<0.05$ compared to untreated group.
$45 \mathrm{~min}$ of bilateral renal artery occlusion did not affect the inhibition of ADA. In our experiments, inhibition of this enzyme in the degradative pathway of cellular ATP leads to a substantial $(20 \%)$ increase in the residual nucleotide pool at the end of the insult. Adenosine was increased by a factor of 2.5, while inosine and hypoxanthine were not detected. According to our biphasic model of ATP recovery, this larger residual nucleotide pool should lead to an increased ATP $_{\text {init }}$. The data from the in vivo ${ }^{31} \mathrm{P}-\mathrm{NMR}$ studies show that $\mathrm{ATP}_{\text {init }}$ is, in fact, enhanced in DCF-treated rats. This finding was confirmed by ${ }^{1} \mathrm{H}-\mathrm{NMR}$ of kidneys extracted after $15 \mathrm{~min}$ of reflow. When the increase in the residual nucleotide pool is compared to $\mathrm{ATP}_{\text {init }}$ determined by ${ }^{31} \mathrm{P}-\mathrm{NMR}$ in vivo, the same correlation between the two quantities as previously noted for various ischemic intervals (8) is found (Fig. 4).

It is possible that DCF also inhibited adenylate deaminase, the enzyme that converts AMP to inosine monophosphate
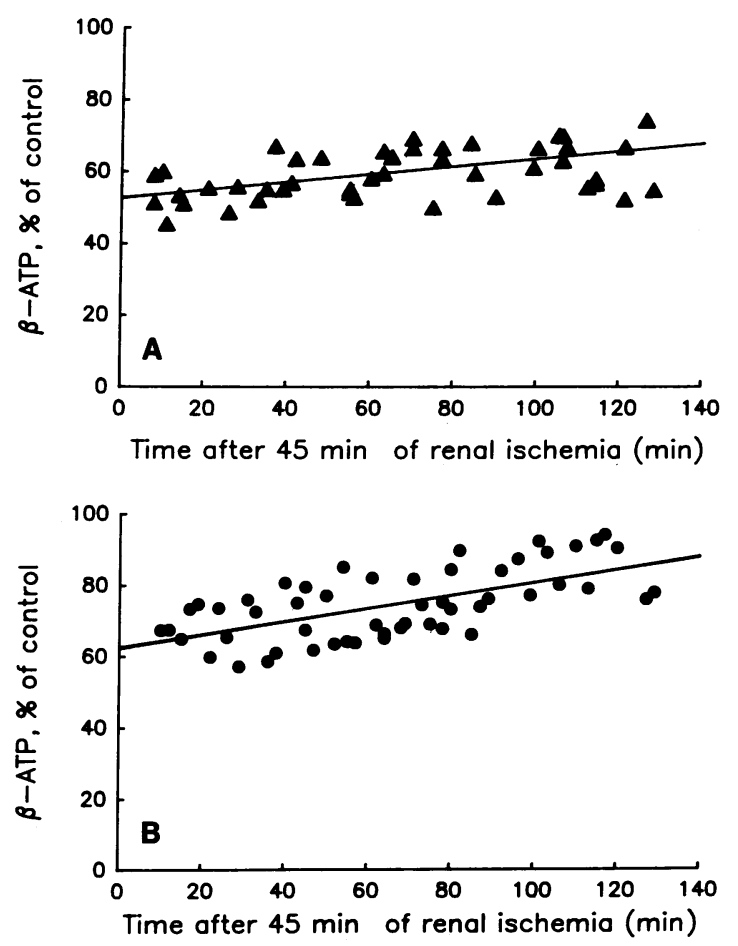

Figure 3. Direct comparison of the rates of recovery of renal ATP after 45 min of ischemia in $(A)$ untreated and $(B)$ DCF-treated rats. Note that DCF-treated animals have increased initial recovery of renal ATP and accelerated rate of net restoration of this high-energy compound. Individual data points are shown for untreated animals $(n=8)$ and DCF-injected rats $(n=7)$. Regression lines calculated by least squares method (see text). 


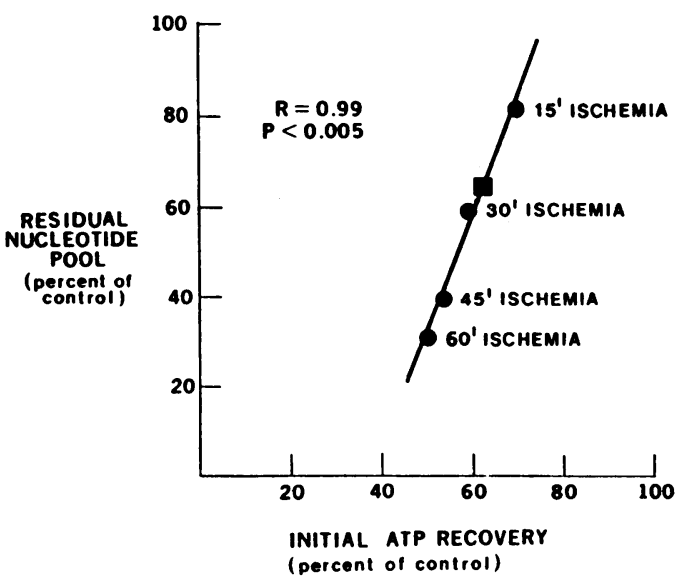

Figure 4. Correlation between the TAN pool in the kidney at the end of an ischemic insult and the rapid initial recovery of renal ATP $\left(\mathrm{ATP}_{\text {init }}\right)$. Note that the increase in both the nucleotide pool and the initial ATP recovery in DCF-treated rats ( $(0)$ follow the correlation as previously reported for untreated animals $(\bullet)$. Data for the various ischemic intervals are from Stromski et al. (8).

(IMP). However, DCF is a much more specific inhibitor of ADA $\left(K_{\mathrm{i}}\right.$ for inhibition $\left.2.5 \times 10^{-12}\right)$ than AMP deaminase $\left(K_{\mathrm{i}}\right.$ for inhibition $\left.2.5 \times 10^{-6}\right)(24,25)$. In addition, Miller et al. (26) found that the conversion of AMP to IMP played little or no role in adenine nucleotide degradation after renal ischemia in rats, dogs, and cats. Moreover, we have found only small amounts of inosine and no IMP in untreated kidneys extracted after $45 \mathrm{~min}$ of ischemia (Fig. 2). Therefore, it seems unlikely that inhibition of adenylate deaminase contributed substantially to the present studies.

The in vivo ${ }^{31} \mathrm{P}-\mathrm{NMR}$ studies demonstrated that the rate of net restoration of renal ATP $\left(\mathrm{ATP}_{\text {slope }}\right)$ was accelerated in DCF-treated rats as compared to control animals. There are several possible explanations for this observation. The ATP slope would be expected to be affected by the amount of cellular and membrane damage and by the availability of precursors for the resynthesis of adenine nucleotides (8). Inhibition of ADA could enhance both these factors. By decreasing the activity of ADA, the flow through xanthine oxidase will be limited during the period of reflow. Xanthine oxidase activity results in oxygen free radical formation, which is known to cause damage to cellular membranes. In fact, it has been reported that inhibition of xanthine oxidase will limit the severity of an ischemic insult (27). DCF, by decreasing the substrate flow through the enzyme, could accomplish the same result.

Our previous studies have shown that postischemic infusion of ATP- $\mathrm{MgCl}_{2}$ or AMP- $\mathrm{MgCl}_{2}$ will significantly increase the rate of ATP resynthesis without altering the residual nucleotide pool $\left(\mathrm{ATP}_{\mathrm{init}}\right)(6,7)$. This effect on the rate of ATP resynthesis is accomplished by providing exogenous precursors for the regeneration of cellular $\operatorname{ATP}(4,7)$. In the present study it would seem most likely that ADA inhibition has not only augmented the residual nucleotide pool but has also increased endogenous precursors available for the resynthesis of renal ATP. Since the DCF is injected intramuscularly and several tissues can have their ADA activity significantly reduced $(13,14,22-25)$, it is possible that there is a systemic increase in the concentration of adenosine. In DCF-treated rats, the tissue content of adenosine was increased. This com- pound could also serve as a precursor for ATP restoration through the action of adenosine kinase. Therefore, the observed increase in $\mathrm{ATP}_{\text {slope }}$ is consistent with both diminished oxygen free radical formation and an augmentation of endogenous precursors for ATP resynthesis.

We have previously observed a correlation between the renal ATP content after 120 min of reflow $\left(\mathrm{ATP}_{120}\right)$ and subsequent functional recovery as determined by $C_{\text {In }}(8)$. Since DCF pretreatment leads to an increased $A T P_{120}$, it would also be expected to lead to enhanced restoration of kidney function. In fact, inhibition of ADA results in a $33 \%$ increase in $C_{\text {In }}$ $24 \mathrm{~h}$ after the injury. When the $C_{\mathrm{In}}$ is compared to $\mathrm{ATP}_{120}$ in the present study,. the same correlation between the two entities as previously noted for various ischemic insults is found (8).

When the results from this study are compared with a prior study from our laboratory (8), an interesting observation is made. The parameters for the postischemic restoration of renal ATP (i.e., $\mathrm{ATP}_{\text {init }}$, the $\mathrm{ATP}_{\text {slope, }}$, and $\mathrm{ATP} \mathrm{P}_{120}$ ) in DCFtreated animals after $\mathbf{4 5} \mathrm{min}$ of ischemia are remarkably similar to those seen in an untreated animal after only $30 \mathrm{~min}$ of injury $\left(\mathrm{ATP}_{\text {init }} 59.1 \pm 3.9 \%\right.$ control; $\mathrm{ATP}_{\text {slope }} 0.17 \pm 0.05 \%$ control/min; $\mathrm{ATP}_{120} 72.8 \pm 6.8 \%$ control). Additionally, pretreatment with DCF prior to a 45-min insult enhances the recovery of function to the level seen after $30 \mathrm{~min}$ of ischemia $(387 \pm 30$ $\mu \mathrm{l} / \mathrm{min} / 100 \mathrm{~g}$ body weight). Therefore, inhibition of ADA during a 45-min interval of renal ischemia reduces the metabolic consequences and functional severity of the injury to that seen after only $30 \mathrm{~min}$ of insult.

The results presented in this study confirm our previously described biphasic model of postischemic ATP recovery determined by ${ }^{31} \mathrm{P}-\mathrm{NMR}$ in vivo and demonstrate that it is possible to partially protect the kidney from an ischemic insult by inhibiting adenine nucleotide degradation. The augmentation of the residual nucleotide pool and diminished flow through the degradative pathway, which results from inhibition of ADA, produces more endogenous precursors for ATP resynthesis, an enhanced initial ATP recovery, an accelerated restoration of cellular ATP, and diminished functional impairment. In fact, inhibition of ATP degradation results in an injury, from the metabolic and functional perspective, which is similar to that of a lesser degree of ischemia.

\section{Acknowledgments}

We thank the Warner Lambert Co. for their generous donation of DCF and Dr. S. M. Fitzpatrick for assistance with the enzyme assay and a special thanks to Elizabeth Foley for typing this manuscript.

This investigation was supported by grants AM-34576 and AM-19930 from the National Institutes of Health and the Netherlands Organization for the Advancement of Pure Research (Z.W.O.) which provided a stipend for A. Van Waarde.

\section{References}

1. Collins, G. M., P. Taft, R. D. Green, R. Ruprecht, and N. A. Halasz. 1981. Adenine nucleotide levels and recovery of function after renal ischemic injury. Transplantation. 31:295-296.

2. Cunningham, S. K., T. V. Keaveny, and P. Fitzgerald. 1974. Effect of allopurinol on tissue ATP, ADP, and AMP concentrations in renal ischaemia. Br. J. Surg. 61:562-565.

3. Fernando, A. R., J. R. Griffiths, E. P. N. O'Donoghue, J. P. Ward, D. M. G. Armstrong, W. F. Hendry, D. Perrett, and J. E. A. 
Wickham. 1976. Enhanced preservation of the ischaemic kidney with inosine. Lancet. 1:555.

4. Gaudio, K. M., M. Stromski, G. Thulin, T. Ardito, M. Kashgarian, and N. J. Siegel. 1986. Postischemic hemodynamics and recovery of renal adenosine triphosphate. Am. J. Physiol. 251:F603-F609.

5. Hems, D. A. and J. T. Brosnan. 1970. Effects of ischaemia on metabolite concentrations in rat liver and kidney in vivo. Biochem. $J$. 120:105-111.

6. Siegel, N. J., M. J. Avison, H. F. Reilly, J. R. Alger, and R. G. Shulman. 1986. Enhanced recovery of renal ATP with postischemic infusion of ATP- $\mathrm{MgCl}_{2}$ determined by ${ }^{31} \mathrm{P}$ NMR. Am. J. Physiol. 245:F530-F534.

7. Stromski, M. E., K. Cooper, G. Thulin, M. J. Avison, K. M. Gaudio, R. G. Shulman, and N. J. Siegel. 1986. Postischemic ATP$\mathrm{MgCl}_{2}$ provides precursors for resynthesis of cellular ATP in rats. Am. J. Physiol. 250:F834-F837.

8. Stromski, M. E., K. Cooper, G. Thulin, K. M. Gaudio, N. J. Siegel, and R. G. Shulman. 1986. Chemical and functional correlates of postischemic renal ATP levels. Proc. Natl. Acad. Sci. USA. 83:6142-6145.

9. Vogt, M. T., and E. Farber. 1968. On the molecular pathology of ischemic renal cell death: reversible and irreversible cellular and mitochondrial metabolic alterations. Am. J. Pathol. 53:1-26.

10. Warnick, C. T., and H. M. Lazarus. 1981. Recovery of nucleotide levels after cell injury. Can. J. Biochem. 59:116-121.

11. Zager, R. A., M. Shaw Jurkowitz, and A. J. Merola. 1985. Responses of the normal rat kidney to sequential ischemic events. Am. J. Physiol. 249:F148-F159.

12. Zager, R. A., L. A. Baltes, H. M. Sharma, and M. S. Jurkowitz. 1984. Responses of the ischemic acute renal failure kidney to additional ischemic events. Kidney Int. 26:689-700.

13. Tedde, A., M. E. Balis, R. Schonberg, and P. P. Trotta. 1979. Effects of 2'-deoxycoformycin infusion on mouse adenosine deaminase. Cancer Res. 39:3044-3050.

14. Trotta, P. P., M. P. Ahland, G. F. Brown, and M. E. Balis. 1978. Studies on the effects of infusion of enzyme inhibitors on adenosine deaminase. Mol. Pharmacol. 14:199-209.

15. Hopkinson, D. A., P. J. L. Cook, and H. Harris. 1969. Further data on the adenosine deaminase (ADA) polymorphism and a report of a new phenotype. Ann. Hum. Genet. (Lond.). 32:361-367.

16. Lowry, O. H., N. J. Rosebrough, A. L. Farr, and R. J. Randall. 1951. Protein measurement with the folin phenol reagent. J. Biol. Chem. 193:265-275.

17. Nelson, S. R., D. W. Schultz, J. V. Passoneau, and O. H. Lowry. 1968. Control of glycogen levels in brain. J. Neurochem. 15:12711279.

18. Kaufman, J. M., N. J. Siegel, and J. P. Hayslett. 1975. Functional and hemodynamic adaptation to progressive renal ablation. Circ. Res. 26:286-293.

19. Foker, J. E., S. Einzig, and T. Wang. 1980. Adenosine metabolism and myocardial preservation: consequences of Adenosine catabolism on myocardial high-energy compounds and tissue blood flow. $J$. Thorac. Cardiovasc. Surg. 80:506-516.

20. Ward, H. B., T. Wang, S. Einzig, R. W. Bianco, and J. E. Foker. 1983. Prevention of ATP catabolism during myocardial ischemia: a preliminary report. J. Surg. Res. 34:292-297.

21. Agarwal, R. P., T. Spector, and R. E. Parks, Jr. 1977. Tightbinding inhibitors. IV. Inhibition of adenosine deaminases by various inhibitors. Biochem. Pharmacol. 26:359-367.

22. Burridge, P. W., V. Paetkau, and J. F. Henderson. 1977. Studies of the relationship between adenosine deaminase and immune function. J. Immunol. 119:675-678.

23. Glazer, R. I. 1980. Adenosine deaminase inhibitors: their role in chemotherapy and immunosuppression. Cancer Chemother. Pharmacol. 4:227-235.

24. Agarwal, R. P., and R. E. Parks. 1977. Potent inhibition of muscle 5'-AMP deaminase by the nucleoside antibiotics coformycin and deoxycoformycin. Biochem. Pharmacol. 26:663-666.

25. Henderson, J. F., L. Brox, G. Zombor, D. Hunting, and C. A. Lomax. 1977. Specificity of adenosine deaminase inhibitors. Biochem. Pharmacol. 26:1967-1972.

26. Miller, W. L., R. A. Thomas, R. M. Berne, and R. Rubio. 1978. Adenosine production in the ischemic kidney. Circ. Res. 43:390-397.

27. Paller, M. S., J. R. Hoidal, and T. F. Ferris. 1984. Oxygen free radicals in ischemic acute renal failure in the rat. J. Clin. Invest. 74:1156-1164. 